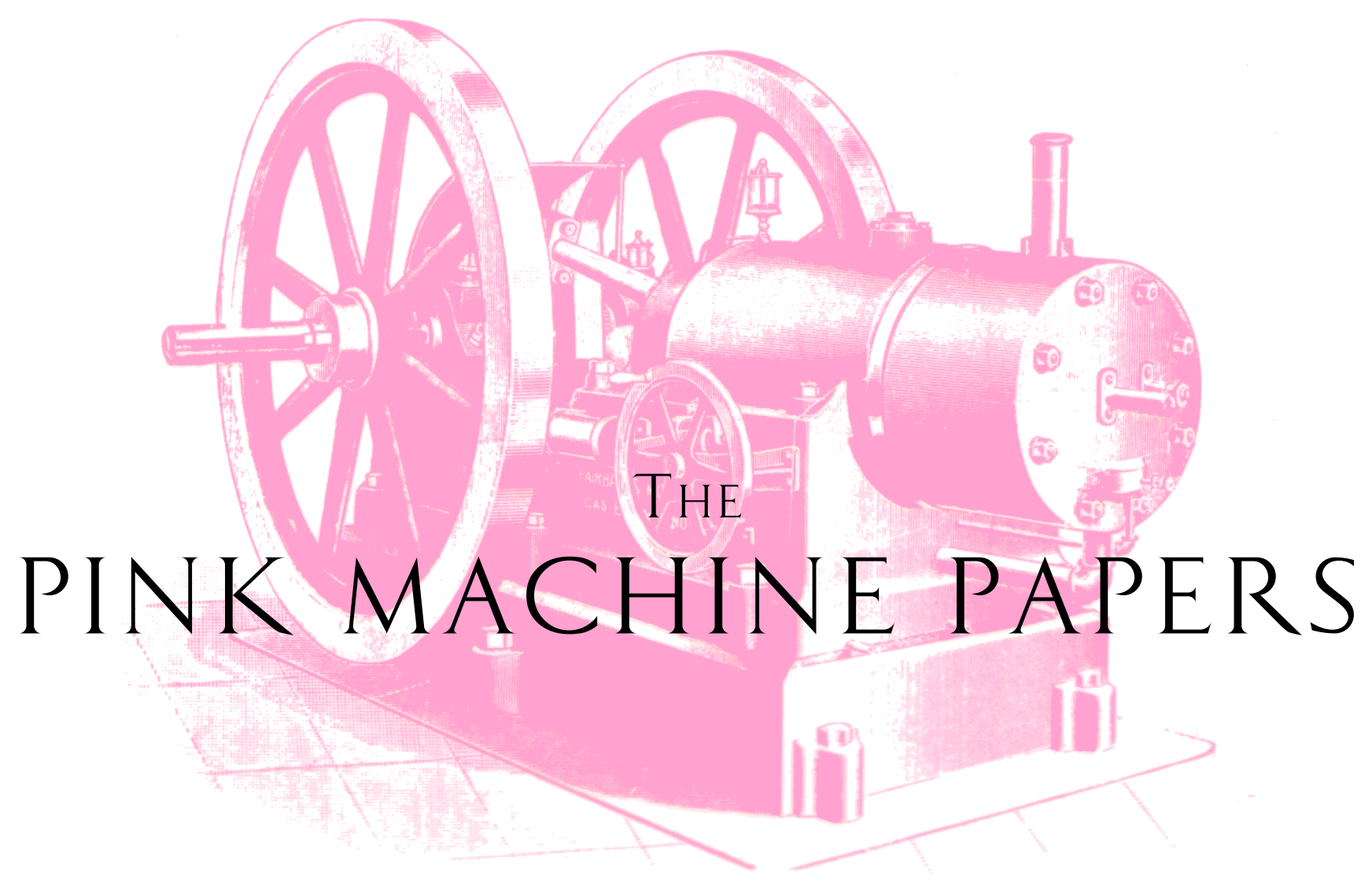

$\#_{3 \mathrm{I}}-\mathrm{N}_{4}^{\mathrm{o}} / 2006$

Methods for Assessing Technology Transfer - An Overview Stefan Görling 


$$
\begin{gathered}
\#_{3 \mathrm{I}} \\
\mathrm{N}_{4}^{\mathrm{o}} / 2006
\end{gathered}
$$

\title{
Methods for Assessing Technology Transfer - An Overview
}

\author{
Stefan Görling \\ Royal Institute of Technology, KTH \\ Dept. of Industrial Management, INDEK \\ Stockholm, Sweden \\ stefan.gorling@indek.kth.se
}

The Pink Machine Papers

ISSN I650- 4062

Stockholm, 2006 


\section{Abstract}

As triple-helix like research funding is growing in popularity, the need for evaluating the success of such programs is growing. During the last 30 years, a number of attempts have been made to assess whether certain technology funding has been successful or not. The purpose of this paper is to present an overview of these attempts as well as suggest that we must look beyond simple valuemeters as patent creation rate in order to fully understand the process of technology transfer.

Keywords: technology transfer, assessment, patent, innovation management Paper type: Research paper 


\section{Introduction}

The increasing popularity of the triple helix as a method of funding research in order to maximize the dissemination of knowledge from university to society, there is a need for further understanding how this dissemination actually takes place as well as estimating and assessing the effects of the research project.

Even though universities has long been regarded a major part of knowledge, technology transfer as a field of research is not more than 30 years old (Niosi 2006).

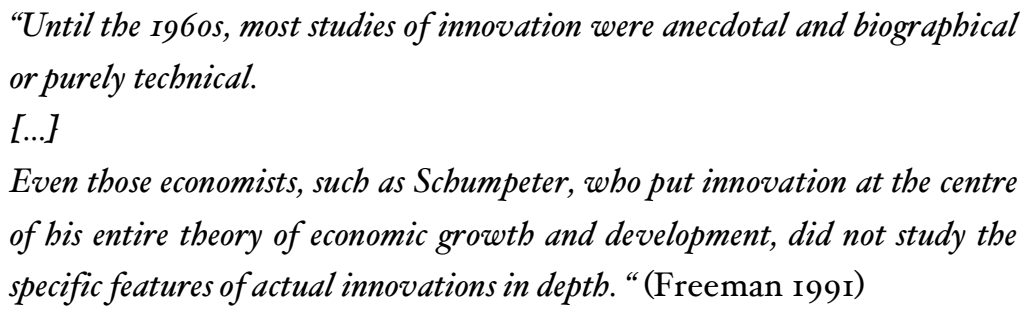

When deciding when to fund a research program or not, the question at hand is whether the project will generate results or not. If one has the luxury of choosing between projects, or the burden of producing evidence that research money is well spent, one has to compare projects and estimate the "value" they have created. To further complicate things, you have to provide these estimates on return on investment upon the decision to fund or not, even though effects of research will not be seen until many years after the research has been conducted. Finally, results are often not a single product but include several, often vague, factors such as "benefit for society" must be included in the calculation.

Previous studies have shown that successful Technology Transfer helps to uplift both the social and economic conditions of society (Madu I989), even though our understanding how this dissemination takes place and what motives and desires drives them still is limited (Bekkers et al. 2006).

In order to be able to predict whether a project will lead to a successful commercialization of a product or the transfer of a technology, we need to study the innovation process more closely, as this is where the foundation is being laid of which the technology transfer itself in many ways only is a natural cause.

"As the parameters of any particular innovations system are not known in advance (and are difficult to measure even in retrospect)" - Heher 2006.

Despite of having a huge research budget, even NASA have little knowledge on how technology is being transferred from their research (Hertzfeld 2002).

"It is necessary to develop more rigorous metrics to assess commercialization activities; commonly collected figures on number of spin-outs and their employees are not sufficiently informative." (Druilhe and Garnsey, 2004) 
Better metrics can act to increase understanding of the risks involved in technology based ventures, which makes it easier to calculate and accepts the risks involved for investors. By having common methods for estimating risks and revenue as well as describing the commercialization process it is easier to build a case for investors.

We therefore have to approach this vast topic, even though many of us would prefer not to.

\section{The triple helix}

The triple helix has been described as an "Innovation in innovation" (Etzkowitz 2003). The idea is that knowledge-producing institutions are developing organizational capacity not only to produce ideas but also to put them into use.

Even though the University traditionally has been a supportive structure for innovation, the triple helix perspective is encouraging the university to actively become involved in the formation of firms and thus evolve into what is referred to as the Entrepreneurial University.

Assessing technology transfer within a triple helix set-up is more complex than in a traditional setting as we have multiple actors, each with a different agenda, participating in the project. What is to be considered a success or not may severely contradict between the actors as each party have a different set of goals to participate in the constellation as compared to a more traditional research project where a single certain organization is involved.

\section{Defining technology transfer}

In order to measure the effects of technology transfer we first have to define what it is. Most commonly it has been defined as licensing of technology from an entity to another. (cf. Philips 2002) In most cases studied the transfer is taking place from a university to another entity such as a major corporation or an incubating company.

Brooks (from Zhao \& Reisman 1992) defines a general concept of technology transfer as:

"Technology transfer is the process by which science and technology are diffused throughout human activity."

Even though there exists a wide range of other scenarios through which technology can be transferred from the university to society, such as licenses, contract research, mobility of scientists, publications of research results etc, much research have focused on university spinoffs based upon patent protected innovations. This alternative is of course only available when knowledge exists in a form that is patentable.

There may exist several reasons for academic studies to focus on the technology transfer process originating in universities. One is of course the simplified access to the empirical data, by studying your own environment. Another is most likely related to the aftermath of the 1980 U.S. Baye-Dole act creating a radical change in the way Intellectual Property (IP) was treated in Universities. 
Entrepreneurial opportunities are often embedded in tacit knowledge and the ability to spot an improvement in the production process due to explicit knowledge of a certain market. In these cases technology is more efficiently transferred through other means, which is often neglected in scholarly studies.

\section{Attempts of taxonomies}

This attempt to produce an overview of this field is not the field, and will most likely not be the last.

Previously, Reisman (1989) have sought to provide a taxonomic view identifying a number of parties in which technology can be transferred between, such as Scienteific disciplines, professions, industries, economic sectors, geographic regions, societies/countries. Reisman \& Zhao (1991) further extends this taxonomian attempts by discussing characteristics of different transaction types. Zhao \& Reisman (1992) identifies the disjointed nature of the technology transfer literature, discussing several possible definitions on technology transfer used in various disciplines. Another attempt to synthesize the voluminous literature on technology transfer have been provided by Bozeman (2000).

Many reasons for the difficulties in technology transfer is well known and has been documented (see Schroer, et al. 1994). Kumar et. Al (1996) work toward creating a taxonomy of motivations to participate in technology transfer activities. The authors have found five categories; economic, social, operational, strategic and personal.

A large number of attempts to assess the efficiency of technology transfer has been carried out and presented in various reviews originating from the large US-based, ATP-funding (summarized in Rueg \& Feller 2003)

\section{Transfer mechanisms}

Since the Baye-Dole act, this idea has spread to several countries where universities are now taking a more active role in patenting ideas and helping scientists to spin-off or transfer their work to other entities. However, a comparison between the Netherlands and the U.S. indicates that USA benefits from their longer experience in this area, both creating more patents and spin-off as well as generating more revenue per spin-off (Bekkers et al. 2006).

The same study found another significant difference, in the Netherlands it is common that the inventor leaves research institute in order to become CEO of the new firm. This is not always a good step as there are rather different qualities needed from a CEO as compared to a researcher.

"On average, the inventors of university technology do not have a comparative advantage in technology commercialization." (Shane 2002) 
Further, the institute suffers from the loss of a member of their team. Such a tradition is in risk to convert the valuable tech transfer into a way of converting great scientists into miserable businessmen. This should be contradicted to the US culture to put a professional manager in charge of the spin-off company.

There exist a large number of methods in which technology is being transferred. The most commonly identified one in literature has been described in the following figure and sections.

\begin{tabular}{|l|l|}
\hline Transfer method & Description \\
\hline Licensing & $\begin{array}{l}\text { Technology is being protected by immaterial law (patents, copy- } \\
\text { right, etc.) and is being licensed to other company. }\end{array}$ \\
\hline Spinning-out/Spinning-off & $\begin{array}{l}\text { Technology is being moved to a separate, new organization in order } \\
\text { to be commercialized. }\end{array}$ \\
\hline Spinning-in & $\begin{array}{l}\text { Technology developed in a cluster/coalition is being commercial- } \\
\text { ized by one of the participating organizations. }\end{array}$ \\
\hline Incubators & $\begin{array}{l}\text { A new company is built within a business incubator, an organiza- } \\
\text { tion specialized in building new companies. }\end{array}$ \\
\hline Procurement & $\begin{array}{l}\text { Knowledge is transferred by for example papers, brochures, word- } \\
\text { of-month, and being absorbed by another company. }\end{array}$ \\
\hline this creating economic incentive to develop it.
\end{tabular}




\section{Licensing}

Most covered in literature is the case of technology licensing, whereas an invention is being patented and then licensed to other actor, which are interested in building services and products based upon this knowledge. A license can either be given exclusively or to several actors. One example of this is the PageRank-technology utilized by Google. This innovation is protected by a patent owned by Stanford, being exclusively licensed to the company until 20II,where after it is possible that several companies may license it thus removing some of the temporary competitive advantage currently held by Google.

Jensen \& Thursby (1998) show using a theoretical analysis that in need for embryonic inventions there is a need for invention co-operation in order to make them usable. Therefore the inventor must be given incentives such as royalties or equity in order to help these inventions evolve into real world products and applications. It is therefore not enough transferring the rights onto the TLOs.

Thus, there exists an interesting conflict where transferring the technology through licenses, such as patents is often inefficient, as the innovations are too embryonic to be of real value for a licensee, and on the other hand having the scientists themselves spinning off a new corporation in order to commercialize the invention, as scientists are seldom good entrepreneurs and that they create a brain-drain.

We know very little of how to predict the probability of success, making estimates unreliable as revenue distribution is uneven - a lion-share of the license revenues is originating from very few projects. (Heher 2006; Scherer \& Harhoff 2000). Therefore, in order to successfully predict the outcome of a patent portfolio, one must have a vast amount of cutting edge research to license from.

Considering this, one might argue that the process of producing patents and licensing inventions rather than simply publishing them is not worth the effort. The counter-argument to this is that the small cost of the Technology Transfer offices (often stated to be $0.3^{-1} \%$ ) is a small price to pay even though the rate of return is low.

Lowe (2006) suggests that, using a game theoretic approach, when knowledge related to an invention is largely tacit (as discussed by Polyani 1958), the inventor either will have to develop the idea via an inventor-founded start-up himself as the knowledge is problematic to transfer, or through a co-operation where the inventor earns royalty so that he is motivated to work to educate the transferee.

Zhao \& Reddy (1993) suggests that the negotiation of technology transfer agreements, especially in an international context, is not only a question of rationally estimating the value of the innovation but also a dynamic interaction between parties which is as much a social process as it is an economic one.

Anton \& Yao (1994) analyze the problem of financially weak independent inventors selling a valuable but easily imitated invention, which cannot be protected by property rights. 
The theory of technology licensing assumes that there exists a 'perfect market' for buying and selling knowledge. A market which has been proved not to work as frictionless as perhaps sometimes assumed, creating the need for other transfer mechanisms.

\section{Spinning-out / Spinning-off}

When a company or research project creates a technology which is interesting in itself, but not directly related to the core business of the organization, an option is to transfer this technology to a separate (new) company.

As previously stated, this has in some countries been the policy to ensure that knowledge created in universities is being utilized in commercial products, thus dissipated into society.

The Lambert Review (2003, p. 5) suggests that there has been too much emphasis on developing university spinouts, many of which proving to be unsustainable instead of focusing on $\mathrm{li}^{-}$ censing the technology.

"On a more general level, doubts are being voiced about whether university spin-outs are the most appropriate vehicle for utilizing research results. For instance, the recent Lambert (2003) review of business-university collaboration...." Libaers 2006.

" $A$ wide range of observers including among others, Rosenberg and Nelson (1994), Etzkowitz et al. (2000), Mansfield (I99I) and Shane (2002), have come to view research-intensive universities as significant agents of technological change and regional economic development." Libaers et. Al. (2006)

"Empirically based studies have identified a range of factors facilitating or bindering the creation and development of spin-outs (Blair and Hitchens, 1998; Chiesa and Piccaluga, 1998; Rappert and Webster, 1998; Smilor et al. 1990; Stankiewicz, 1994; Weatherston, 1993)”(Druilhe \& Garnsey 2004)

Due to this and other raised critique of the spinout as a way to create bad businessmen from great scientists, policy makers in many levels moving away from this idea. Instead there is a growing appreciation for the principles lying behind the triple-helix-constellation and the prospects of generating spillovers and spin-in as a result of researchers and corporation meeting in research-projects consisting of many actors.

\section{Incubators}

A special field of spin-out studies is when the technology is being commercialized by an incubator. While much of the research studying spin-outs in general still is valid for these new companies it is also important to note the research which has been done specifically to asses the efficiency of technology business incubators.

Most notably is the research carried out by Philips (2002), who studied a number of technology business incubators found that few actually were using university-based technology. Phil- 
ips further concludes that few comprehensive studies have been carried out regarding the effectiveness of technology incubators as mechanisms for technology transfer.

He further found that incubator programs are not efficient technology transfer mechanism, despite the fact that many were established with that goal in mind.

\section{Spinning-in}

In research-projects with multiple actors technology created by the project group must be spun-back into one or several of the organization in order to be commercialized. How this is being done has not yet been fully discussed by researchers, needing further attention in a world where triple-helix constellations is growing more common due to its increased popularity within the areas of research policy and funding.

\section{Procurement}

In order to decrease risks of developing a new technology or product it is possible to motivate this development by procurement. Traditionally this method has been used by governments in order to develop military technology or in order to stimulate the development of national companies instead of purchasing a similar technology from outside the country.

Sweden once had a great tradition of governmental procurement where companies such as Ericsson, ASEA (ABB), and AGA to name a few were getting orders to develop new products. Instead of purchasing existing Lighthouses from abroad, Swedish naval authorities asked AGA to develop own so that they could be utilized. The research and development costs where thus guaranteed by a first customer, while they were able to keep the ownership of the technology. Several Swedish companies, which grew large during the 20 th century, were founded upon this principle.

Today, partly as a process of becoming a member of the European Union as well as other changes in purchasing policies, this method is now limited to the procurement of military product, while it is still being utilized more in other countries.

\section{Spillover \& absorption}

Much knowledge and technology is being dissipated through society in less formal methods. Knowledge is 'spilling over' between organizations, industries and countries in many ways, such as the publishing of academic papers, people changing workplaces, methods of reverseengineering products, industrial espionage and even late night pub crawls. This knowledge can then be absorbed and utilized by $R \& D$ departments in other organizations.

"Knowledge spillovers are important to the productivity of firms (Faffe, 1986) and to economic growth (Griliches, 1992; Romer, 1990).”(Lim 2004)

"The best form of knowledge transfer comes when a talented researcher moves out of the university into business, or vice versa. [...] Encouraging academics and business people to spend more time together should be a bigh priority." (Lambert 2003) 
Nataraajan \& Chawla (I994) identifies that technology transfer is not always carried out in formal controlled ways but that there exists random transfer of technology, which the authors claim to be an unexplored phenomenon.

\section{| Measuring technology transfer}

The approaches to measure the success and effects of technology being transferred could be divided into either quantitative or qualitative approaches. In this section, some of the attempts, which have been reported through academic publishing, will be presented.

\section{Quantitative approaches}

Bozeman (2000) describes a number of different policy paradigms which exists in the literature, namely market failure policy, mission technology, cooperative technology policy. And goes on defining a model for organizing the literature called the Contingent Effectiveness model of technology transfer which takes into consideration that parties to technology transfer have multiple goals and effectiveness criteria.

Bekkers et al. (2006) have tried to develop a more complete and structured understanding of factors determining the effectiveness of IP-based spin-offs.

"During the past decade, many evaluation studies have been produced using either Market Impact or Economic Development criteria, or both. (Bozeman 2000)

Chapman (I994) presents one of the few attempts to develop output measures for technology transfers. He has identified a number of input measures (telephone calls; company visits; newsletters; etc.) as well as output measures (jobs created or saved; increase in revenues, new products, etc.).

Bernad et al (1995) presents a case study on measuring the performance of technology transfer, using measurements models from Chapman (1994) they study the efficiency of the technology transfer center at the University of Alabama. Finding that the input measurements are easy to collect and tabulate, but that output measures are difficult to obtain merely I.5 years after the creation of the office.

Hertzfeld (2002) used a methodology previously used to measure the European Space Programs (Bach, I992), by identifying a number of positive outputs (such as new products, commercial benefits due to reputation, development of labor skill, etc. ) and creating measurements for them unable to assess the value added to a company participating in a NASA research program. 


\section{Counting patents}

The far most common method found evaluating R\&D funding found in this literature study is the use of patents as a valuemeter.

Several scholars (c.f. Jaffe and Lerner 200I) uses patents per R\&D dollar as a mean to compare the efficiency of universities versus research laboratories, while recognizing that it would be desirable to other indicators of technology transfer they are unfortunate enough to have limited and inconsistent data in other areas.

Patents are indeed a convenient valuemeter as it is easily countable, exists in public registers and is an unquestionable sign of a research result.

However, as quantitively attractive this measure is, the quantitively unattractive it is. The patent may be a sign of research, but it is far from representative to measure the effects of a certain technology transfer effort.

Measuring patent output over time is a problematic process as the patent system has gone through a number of changes in policies and practices. (Jaffe 1999) It is therefore hard to single out whether an increase in patents from a certain institute is the result of more innovative or efficient research operations rather than patent policy changes.

Hall et al. (200I) suggests that counting things in order to estimate technology transfer efficiency should be complemented by estimating the value of them is a more desirable approach.

D.S. Siegel et al. (2003) utilizes a more advanced method (Griliches, 1998), trying to take into consideration 3 outputs: number of new products, number of patents, number of copyrights, generated from two inputs: $R \& D$ Expenditures and number of scientists to search for a correlation that indicates whether university research parks are slightly more productive than pure university environments or not.

Agrawal \& Henderson (2002), working in the same spirit as Cohen (Cohen et al. 1998) studied the knowledge transfer from two departments at MIT. Due to the vast amount of available data, patents have bee been extensively used in previous quantitative studies (Jaffe 1989; Henderson et al. 1998) as well as measurements new firms created by licenses (Gregorio \& Shane 2000; Jensen \& Thursby 1998; Thursby and Thursby 2000).

\section{"A focus on patents and licensing as an important mechanism of knowledge transfer from universities to the private sector is thus understandable. How- ever, it is almost certainly incomplete. "(Agrawal \& Henderson 2002)}

The authors critiques these measurements as their study concludes that patents is only a minor part of the knowledge transfer from the university and therefore not a representative valuemeter.

Which also is consistent with Cohen et al. (2002) 
"Contrary to the notion that university research largely generates new ideas for industrial $R \& D$ projects, the survey responses demonstrate that public research both suggests new $R \& D$ projects and contributes to the completion $o$ existing projects in roughly equal measure overall. The results also indicate that the key chan- nels through which university research impacts industrial $R \& D$ include published papers and reports, public conferences and meetings, informal information exchange, and consulting. We also find that, after controlling for industry, the influence of public research on industrial $R \leftrightarrow D$ is disproportionately greater for larger firms as well as start-ups."

(Cohen et al. 2002)

Reasons for patenting university inventions, may not only be to secure revenues for the university, as these are often limited or non-existent. The patent may also act as a way to protect a possible licensee from competition, so that they can invest in all the follow-up work needed by the industry in order to make it usable. (Colyvas et al. 2002)

\section{Return on Investment (ROI)}

Heher (2006) seeks to predict future returns of investments in public research. By using a combination of institutional return on investment models and a simple economic projection he seeks to address unrealistic expectations from countries now seeking to increase their efforts to commercialize their research results.

The normal process of technology transfer involves a number of steps, each taking a few years. Therefore, there is typically 6-1o years elapsing from the initial disclosure of an invention until a patent license is generating a significant income. Considering this, time from investment until a potential payback of invested money is most likely Io-20 years ahead of time.

Besette (2003) approaches the increasing problem of calculating profitability from research by suggesting Return on Investment (ROI) as a comparative measure as compared to previous university tradition to measure peer review, which has little benefit for economic stakeholder. By estimating all costs and benefits for each stakeholder a return of investment can be calculated for each stakeholder (as different stakeholders may benefit from different outputs) or weighted together to a compound index. Besette suggests a number of potential outputs, not without recognizing that quantification and measurement of these might be problematic in many cases.

\section{Qualitative approaches}

While there have been a lot of attempts to quantitatively assess the effects of technology transfer, qualitative approaches have not been as thoughtfully discussed in the current literature.

Colyvas et al. (2002) seeks to learn more how university inventions get into practice by studying a number of cases. 
"Not only do the findings from these interviewes clearly show the very complex paths that eventually moved the products to marketplace, but that the path varied dramatically for any particular technology" (Hertzfeld 2002)

Spin-outs and technology transfer projects are often being treated as homogeneous even though each projects have its own characteristics and differ to a great extent. Druilhe \& Garnsey (2004) studies university spin-outs using a Cambridge University database and argues that we need a better understanding of the heterogeneity of spin-outs as the diversity have both theoretical and policy implications.

\section{Assessment challenges}

In this section a number of challenges identified in the literature is being presented in order to create a list of issues, which needs further attention when designing studies associated with technology transfer in the future.

\section{Perspectives}

When assessing the success of a project it is important to define from which perspective one is performing the assessment. A certain project might be a success from a societal perspective, but a failure for a participating organization or individual (or vice verse).

There also exists a delimitation problem in which benefits and costs that should be related to the project itself, as illustrated by Bozeman:

\section{"If a new drill bit project enables deeper drilling opening up North Sea oil ex- ploration (Link, 1995), how much does one credit the project and prior sci- ence? How quickly would the technology have developed if not for the pro- ject? Most important, if a US developed technology provides great benefits abroad, what does that do to the accounting?" (Bozeman 2000)}

An early attempt to assess social and private rates of return from industrial innovations was presented by Mansfield et al. (1977). Mansfield sought to estimate changes in marginal costs, affects on product prices and using these to estimate the full rate of return on innovations.

In a more recent study, Link \& Scott (2005) illustrates field-based methods for measuring the social rates of return to innovative investments. They studied the development of an improved standard reference material (SRM) for the measurement of the wavelength of light in an optical fiber network, used to calibrate instruments. Link \& Scott builds upon the method pioneered by Griliches and Mansfield exemplifying the practical work of assessing the quantification of benefits and costs and the calculation of a rate of return utilizing Net Present Value. 


\section{Defining success}

The concept of success is in itself complicated and diffuses. Is a project successful if a certain number of patents is the outcome, or do we need to take into consideration whether this patent actually is being licensed or not?

"This absence of information is surprising since researchers have recognized that approximately half of all university patents are never licensed, and that licensing activity is not randomly distributed across patents (fensen and Thursby 2001, Hsu and Bernstein 1997, Barnes et al. 1997)”Shane (2002)

Is the creation of a new organization a sign or success, or do we need to take into consideration whether this corporation survives for a number of year and becomes profitable?

"The assumption of the Out-the-Door criterion is that transfer itself equates with success" (Bozeman 2000)

"One reason of the Out-the-Door criteria is likely to take on even more importance than in the past is the increased concern for quantitative demonstration of results. In the US, the Government Performance and Results Act (GPRA) (US Congress, 1993) has contributed in part of the "metric mania" now gripping the US federal bureaucracy." (Bozeman 2000)

Research is not only carried out to develop and commercialize technologies, but also to strengthen the overall knowledge body at corporations and research institutes. Bozeman et al. (1999) feel that scientific and technical human capital is often neglected and underestimated. Even though a research project might not have yielded any direct results, it might have supplied the researchers with knowledge, which affects their next project.

Tödtling \& Kaufmann (2002) studies SMEs in upper Austria which have received innovation support, finding that those who have received support are more innovative than those who haven't, that SMEs in general co-operate with local partners and that most innovation still is linear although there has been a shift into more interactive innovation.

Due to the fact that most studies of spin-outs concern ventures that have actually become operational enterprises (From Druilhe \& Garnsey 2004: Blair and Hitchens, 1998;Brett et al., I991; Chiesa and Piccaluga, I998; Downes and Eadie, I998; Rappert and Webster 1998, Roberts and Malone, 1996; Smior et al. 1990) there exists a bias which we must take into consideration.

"The survival bias in these studies reflects the difficulty of obtaining evidence on scientists' intentions to commercialize research findings if these do not actually eventuate as incorporated ventures." (Druilhe \& Garnsey 2004) 


\section{Skewness of returns}

Scherer \& Harhoff (2000) combines eight sets of data on inventions and innovations in order to assess the size and distribution of financial returns. They found that the outcomes where skew where the lion's share of all value originated from a small number of projects. This suggests that one must use portfolio theory, supporting a large number of projects in order to limit risk. This skewness increases further the need for early assessment of project potential.

\section{Time to market}

It is hard to generalize the time it takes from invention to commercialization; further, different technologies have different timelines (Power \& Morris 2004).

There exists a large number of other factors affects the time-to-market process, such as project organization, up-front planning and market activities (Cooper 1994, from Powell \& Morris 2004)

"In general, small companies see market entry as more urgent for cash-flow reasons. They may be under pressure to satisfy outside investors, and therefore may be more eager to launch early products whether or not these embody the full technological potential (Powell 1999)" (Powell \& Morris 2004)

\section{Transforming knowledge}

"As time passes, an increasing amount of the technology diffuses and it becomes "common knowledge". Hence, the knowledge becomes easier to absorb (Reagans and McEvily, 2003), and the need to work intimately with knowledge suppliers declines." (Lim 2004)

Bach et al. (2002) suggests, drawing upon experience from the European Space Programs that there exits many differences in how technology is being, and can be transferred depending on the nature of the project. In some cases space-technologies are to specific so that the cost and effort of modifying these for other industry-use takes longer time than developing the technology without space-technology co-operation. Further they recognize that the potential for successful TT is dependent upon whether the research programs are mission- or diffusionrelated, and that generic technologies need a very long time in order to generate large profits whereas specific technologies generally reaches an industrial application more rapidly.

Chakrabarti \& Anyawu (1993) tried to trace the flow of military technology to the civilian sector in order to determine the impact of defense expenditure on technological change. They found out that there was no statistically significant evidence of resource diversion on the civilian economy due to defense $\mathrm{R} \& \mathrm{D}$. They further argued that market conditions differ significantly in the defense and civilian sectors making it difficult to transfer products from one area to another. 
Even though the authors finds several papers concluding that the mechanisms within the defense sector are not suitable for effective technology transfer, they also find support for the fact that some industries has been stimulated by defense procurement and sponsorship of $\mathrm{R}$ $\& \mathrm{D}$, such as the electronics and aviation industries.

There certainly exist cases where we have seen that spin-offs have made a difference. A study in the Netherlands carried out in 2002 (Biopartner) showed that $44 \%$ of all the life science firms founded in the Netherlands between I990 and 2002 are spin-offs.

\section{Absorbing knowledge}

Cohen \& Levinthal (1989) claims that economics in general previously have assumed that technological knowledge, which is in the public domain, can be costless realized by all firms. Arguing that there is a cost in absorbing and applying technology, therefore, organizations are dependent on their own internal R\&D capacity even if other party is conducting most research. One reason for this is that outside knowledge is less targeted to the particular need of the firm and therefore must be recognized and adapted in order to be adopted.

\section{"Economists conventionally think of $R \& D$ as generating one product: new information. We suggest that $R \dot{U} D$ not only regenerates nere information, but also enbances the firm's ability to assimilate and exploit existing informa- tion."(Cohen \& Levinthal I989) \\ "Scholars of technological change have observed that firms invest in own $R \& D$ to be able to utilize information which is available externally (e.g. Til- ton, 1971; Allen, 1977; Mowery, 1983)" (Cohen \& Levinthal 1989)}

Absorptive capacity represents an important part of a firm's ability to create new knowledge (Cohen \& Levinthal I989).

Freeman (1991) agrees that: "the problem of innovation is to process and convert information from diverse sources into useful knowledge about designing, making and selling new products and processes." This, the problem is not always that there is a need for more research, but that we have to find the right knowledge, combine it and apply it.

Lim (2004) proposes three kinds of absorptive capacity: disciplinary, domain-specific and encoded and argues that absorptive capacity is dependent both on internal R\&D as well as social networks.

"While surveying of two decades of research in this area, Lane, Koka and Pathak (2002) point out that the literature has places "little attention to the actual processes underlying absorptive capacity"'

In his later works, Schumpeter presented a hypothesis of a positive linkage between market power and innovation, based upon the thesis that it is the larger corporation that can provide 
the necessary resources to conduct extensive R\&D. Love \& Roper (I999) have tried to extend this view by developing formal indicator's of firms' technology transfer and networking intensity, arguing that "technology transfer and networking may be important alternatives to R\&D as an input into the innovation process".

\section{Other factors affecting technology transfer}

Finally, one must recognize that technology transfer is highly affected by other factors, such as policies, bureaucracy and many others.

\section{Policies}

Several scholars suggest that the policies regarding technology transfer play an important role in how innovations will be patented and commercialized (cf. Argyres \& Liebeskind I998; Di Gregorio \& Shane 2003). This is not limited to policies of individual research institutes but also affected by regional and national policies. (OECD 2003; Nerkar \& Shane 2003)

\section{Bureaucracy}

Hertzfeld (2002) identifies that bureaucracy such as complex and time-consuming federal government procurement procedures, IP-rights, etc. slows down the introduction to the marketplace, in worst case making the inventions aged and without commercial value once they are ready to be commercialized. In some cases one could make the argument that it might be better not to patent inventions. There are cases where a patent also acts as a warrant for the licensee, investing in commercializing the product, that they will be the only company pursuing this.

\section{Findings from the SAPPHO project}

The SAPPHO project measured around a hundred characteristics of 40 paris of innovations. Some of the most important hypothesis was: (As listed in Freeman I99I)

I) Successful innovations were characterized by determined attempts to develop an understanding of the special needs and circumstances of potential future users. $\left(\mathrm{Nu}^{-}\right.$ merous studies have supported this claim thereafter., cf. Lundvall)

2) Successful innovators developed techniques to integrate marketing activities at an early stage of the development work.

3) Linkage with external sources of scientific and technical information and advice. Successful innovators combined in-house R\&D with other sources of technology.

4) Concentration of high quality $R \& D$ resources on the innovate project.

5) High status, wide experience and seniority of the "business innovator"

6) The existence of in-house basic research. Important mainly because of the linkages to external networks, especially universities. 


\section{The market for technology transfer and its limits}

Even though there exists several success stories of technology transfer, such as when Libaers et al. (2006) shows that University spin-outs plays an important role in the emerging field of nanotechnology we must recognize the natural limitation of it.

First of all, many corporations are not based upon the absorption or commercialization of new knowledge. The largest part of our economy is occupied with providing products and services, which sometimes have been known for hundreds of years. Even when considering more advanced industries there exists evidence that the technology transfer market plays merely a marginal part of innovation and R\&D.

"Nelson (1986) and Klevorick et al. (1995) interpreted their findings to suggest that recent university research (i.e., conducted in the prior $10-15$ years) had little direct effect on industrial R\&D outside a few technologies such as drugs, other areas of medicine, sophisticated organic chemical products, and some areas of electronics." (Cohen et al 2002)

Instead of having a link from public research to industrial $\mathrm{R} \& \mathrm{D}$, Cohen et al. (2002) finds (consistent with von Hippel 1988), that much of industrial R\&D is initiated because of feedback from customers or internal manufacturing.

These differences can be discussed as the difference between push and pull technologies, as whether the technology is the result of a request from customers (being pulled from researchers), or whether there exists a technology which someone thinks might have a market (technology being pushed from researchers to market).

"Focusing on technology transfer from defense laboratories, Spivey et al. (1997) found that defense laboratories tend to employ technology push in transferring technology to civilian use but market-pull when technology is transitioned to defense operations and field agencies."

(From Bozeman 2000)

Further, the current market for the trade of patents and inventions is limited and knowledge is often hard to package in a way so that it can easily be transferred from one party to another.

Shane (2002) argues that we lack systematic explanation of which university inventions will be licensed and commercialized, or who will conduct it. By drawing on transaction cost literature he seeks to identify conditions under which university technology will be successfully licensed and commercialized. Finding that "inventions are more likely to be licensed when patents are an effective mechanism for appropriating the returns to innovation because the patent system reduces the transaction costs of technology transfer." 
Patents creates a market for trade, so that inventions can be commercialized by another party than the inventor himself. Thus, in theory, increasing the benefit for all parties.

"The results provide evidence that university inventors become entrepreneurs because of failures in the market for knowledge, suggesting that inventor entrepreneurship is a second-best solution to the commercialization of new technology.”(Shane 2002)

\section{Discussion - Towards a qualitative research agenda}

As presented in this paper, previous research on technology transfer has to a large extent been based upon quantitative methods, in many cases using simple valuemeters such as counting patents.

However, as the these results, such as return of investment and licensed patents only is measurable several years after the end of the project, these are inadequate for assessing whether a certain research project will be successful or not.

"The interactions between the participants to a given program dramatically shape the resulting paths of technological transfer. The way participants exchange information and knowledge, the choice of their coordinating devices, and the mutual degree of trust within their network influence to a large extent the intensity of technological transfers from the program"

(Bach et al. 2002)

The quantitative approach also gives us little understanding about the process itself. Further more qualitative research in the field of technology transfer is therefore needed in order to fully understand the process of innovation taking place within R\&D-settings.

"People involved in RひD interact continuously. It is often difficult to separate the researcher from the production manager

[...]

$R \& D$ is a complex and interactive process. There is no single most effective correct way to predict how the funding of $R \& D$ might evolve into a commercial product." (Hertzfeld 2002)

There exists a need to build a qualitative research agenda by incorporating theories of entrepreneurship, innovation and creativity into a multi-disciplinary approach. It is only by understanding these processes can be able to predict whether certain research projects may be successful or not, counting the number of patents afterwards yields little knowledge about which initial parameters was responsible for the success or failures.

The increasing popularity of funding triple-helix constellations also builds the need for a deeper understanding in the problems and potential of Spin-ins, transferring technology from 
a joint project back to one of the participating organizations. It is not until we understand this transfer of technology we can fully assess whether the triple-helix constellation is a successful way to organize research or not. 


\section{References}

Agrawal, A. \& Henderson, R. (2002), Putting Patents in Context: Exploring Knowledge Transfer from MIT, Management Science vol. 48, no. I, pp. 44-6o

Argyres, N. \& J. Liebeskind (I998), Privatizing the Intellectual Commons: Universities and the Commercialisation of Biotechnology, Fournal of Economic behaviour and Organization $35,427-454$

Anton \& Dennis (I994), Expropriation and Inventions: Appropriable Rents in the Absence of Property Rights, The American Economic Review, Vol. 83, No. I, pp. 190-209

Bach et al. (2002), Technological Transfers from the European Space Programs: A Dynamic View and Comparison with Other R\&D Projects, fournal of Technology Transfer, 27, 32 I $^{-}$ 338

Bekkers, Gilsing \& Steen (2006), Determining Factgors of the Effectiveness of IP-based Spin-offs: Comparing the Netherlands and the US, fournal of Technology Transfer, $3 I$, $545-566$

Bernard et al. (I995), Measuring Technology Transfer Performance: A Case Study, fournal of Technology Transfer, September 1995.

Bessette, R. (2003), Measuring the Economic Impact of University-Based Research, fournal of Technology Transfer, 28, 355-36I

Biopartner (2002), The Netherlands Life Sciences Sector Report 2002, Ede. The Netherlands

Bozeman (2000), Technology transfer and public policy: a review of research and theory, $R e^{-}$ search Policy 29, 627-655

Chakrabarti \& Anyawu (I993), Defense R \& D, Technology, and Economic Performance: A Longitudinal Analysis of the U.S. Experience, IEEE Transactions on Engineering Management, vol. 40, No 2, May 1993.

Cohen, W. M. \& Levinthal, D. A. (I989), Innovation and Learning: The Two Faces of $R$ \& D, The Economic Journal, Vol. 99, No. 397, pp. 569-596

Cohen, W.M., Nelson, R.R., Walsh, J.P. (2002), Links and Impacts: The influence of Public Research on Industrial R\&D, Managmenet Science, Vol. 48, No. I, pp. I-23

Colyvas et al. (2002), How Do University Inventions Get Into Practice?, Management Science 2002, Vol. 48, No. I, pp. $61^{-} 7^{2}$

Di Gregorio, D. and S. Shane (2003), 'Why do Some Universities generate More Startups Than others?', Research Policy 32, 209-227

Druilhe \& Garnsey (2004), Do Academic Spin-Outs Differ and Does it Matter?, fournal of Technology Transfer, 29, 269-285

Etzkowitz Henry (2003), Innovation in innovation: the Triple Helix of university-industrygovernment relations, Social Science Information 42(3), pp. $293-337$

Freeman, C. (1991), Networks of innovators: A syntesis of research issues, Research Policy 20, 499-514

Griliches, Z. (I998), R\&D and Productivity: The Econometric Evidence, National Bureau of Economic Research for the University of Chichago Press, Chicago

Hall, B. H., Javve, A.B., Trajtenberg, M. (200I), The NBER patent citations data file: lessons, insights, and methodological tools., NBER Working Paper \#8498

Heher, A. D. (2006), Return on Investment in Innovation: Implications for Institutions and National Agencies, Fournal of Technology Transfer, 3I, 403-4I4.

Hertzfeld, H. (2002), Measuring the Economic Returns from Successful NASA Life Sciences Technology Transfers, Fournal of Technology Transfer, 27, 311-320

Jaffe, A. (I999), The U.S. Patent System in Transition: Policy Innovation and the Innovation Process, Working paper 7280 , Nber working paper series.

Jaffe, A. \& Lerner, J. (200I), Reinventing public R\&D: patent policy and the commercialization of national laboratory technologies, $R A N D$ Fournal of Economics, Vol. 32, No. I, $p p$. $167^{-19} 8$ 
Jensen R \& Thursby M (I998), Proofs and prototypes for sale: the tale of university licensing, NBER Working Paper 6698

Kumar et al. (1996), Transfer of Technology: A Classification of Motivations, Fournal of Technology Transfer, Spring-Summer 1996

Lambert Review (2003), Lambert Review of Business-University Cooperation

Lim, K. (2004), The Many Faces of Absorptive Capacity: Spillovers of Copper Interconnect Technology for Semiconductor Chips

Link \& Scott (2005), Evaluating Public Sector R\&D Programs: The Advanced Technology Program's Investment in Wavelength References for Optical Fiber Communications, Journal of Technology Transfer 30 1/2, $24 I^{-2} 5^{I}$

Lowe, R. (2006), Who Develops a University Invention? - The Impact of Tacit Knowledge and Licensing Policies, Fournal of Tech Transfer, 3I, 415-429

Love, J. \& Roper, S. (I999), The Determinants of Innovation: R\&D, Technology Transfer and Networking Effects.

Mansfield et al. (1977), Social and Private Rates of Return from Industrial innovations, The Quaterly fournal of Economics, Vol. 9I, No. 2, pp. $22 I^{-2} 4^{\circ}$

Nataraajan \& Chawla (I994), Random Transfer of Technology: An Unexplored Phenomenon, fournal of Technology Transfer

Nerkar, A. and S. Shane (2003), 'When do Start-Ups that Exploit Patented Academic Knowledge Survive?', International fournal of Industrial Organization 2I, I29I-I4IO

Niosi, Jorge (2006), Universities as a Source of Commercial Technology, fournal of Technology Transfer, 31, 399-402, 2006

Philips R. G. (2002), Technology business incubators: how effective as technology transfer mechanisms?, Technology in Society 24, 299-316

Powell \& Moris (2004), Different Timelines for Different Technologies, fournal of Technology Transfer, 29, $125^{-152}$

Scherer \& Harhoff (2000), Technology policy for a world of skew-distributed outcomes, $R e^{-}$ search Policy 29, 559-566

Shane, S. (2002), Selling University Technology: Patterns from MIT, Management Science Vol. 48, No. I, pp. $122-137$

Reisman, A. (I989), Technology transfer: A taxonomic view, technology transfer summer-fall 1989

Reisman \& Zhao (I99I), A Taxonomy of technology transfer transaction types, fournal of Technology Transfer

Ruegg \& Feller (2003), A Toolkit for Evaluating Public R\&D Investment: Models, Methods and Findings from ATP's First Decade, http://wwr.atp.nist.gov/eao/gcro3-857/contents.htm

Tödtling \& Kaufmann (2002), SMEs in Regional innovation Systems and the Role of Innovation support - The Case of Upper Austria, Fournal of Technology Transfer, Vol. 27, 15-26

Zhao \& Reisman (I992), Toward Meta Research on Technology Transfer, IEEE Transactions on engineering management, Vol. 39, No. I,

Zhao \& Reddy (I993), Managing international technology transfer negotiation: a social exchange perspective, Technovation Volume 13, No 6. 
Pink Machine is the name of a research project currently carried out at the Department of Industrial Economics and Management at the Royal Institute of Technology, Stockholm. It aims to study the often forgotten non-serious driving forces of technical and economical development. We live indeed in the reality of the artificial, one in which technology has created, constructed and reshaped almost everything that surrounds us. If we look around us in the modern world, we see that it consists of things, of artefacts. Even the immaterial is formed and created by technology - driven by the imperative of the economic rationale.

As Lev Vygotsky and Susanne Langer have pointed out, all things around us, all these technological wonders, have their first origin in someone's fantasies, dreams, hallucinations and visions. These things, which through their demand govern local and global economical processes, have little to do with what we usually regard as "basic human needs". It is rather so, it could be argued, that the economy at large is governed by human's unbounded thirst for jewellery, toys and entertainment. For some reason - the inherent urge of science for being taken seriously, maybe - these aspects have been recognised only in a very limited way within technological and economical research.

The seriousness of science is grey, Goethe said, whereas the colour of life glows green. We want to bring forward yet another colour, that of frivolity, and it is pink.

The Pink Machine Papers is our attempt to widen the perspective a bit, to give science a streak of pink. We would like to create a forum for half-finished scientific reports, of philosophical guesses and drafts. We want thus to conduct a dialogue which is based on current research and which gives us the opportunity to present our scientific ideas before we develop them into concluding and rigid - grey reports and theses.

Finally: the name "Pink Machine" comes from an interview carried out in connection with heavy industrial constructions, where the buyer of a diesel power plant worth several hundred million dollars confessed that he would have preferred his machines to be pink.

\section{Claes Gustafsson}

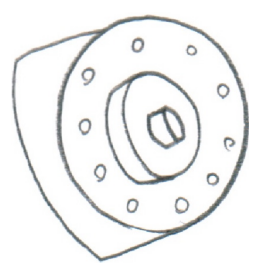

also available at 